\title{
A Educação Musical e os Novos Tempos da Educação Brasileira
}

\author{
Sérgio Luiz Ferreira de Figueiredo
}

Este artigo apresenta uma visão panorâmica sobre a educação musical no Brasil, focalizando sinteticamente vários momentos históricos onde se desenvolveram práticas educacionais diversas. A legislação brasileira apresenta novas perspectivas para a educação musical nas escolas. O texto também mostra uma experiência concreta no município de Florianópolis, SC, onde uma parceria entre a Universidade e a Secretaria de Educaçāo tem contribuído para o estabelecimento de uma ação efetiva em termos de educação musical.

\section{Introdução}

A educação musical nas escolas brasileiras está diretamente relacionada a diversos modos de pensar sobre a função da música na formação dos indivíduos. Música pode ser compreendida como lazer ou entretenimento, enfatizando seu caráter social; música como instrumento de controle e disciplina, enfatizando questões cívicas e morais; música como forma de conhecimento, abarcando aspectos da cognição humana. Seja qual for o objetivo da educação musical, tal atividade tem sido relegada a um plano secundário e muitas vezes está apenas atrelada a uma 'educação artística' escolar, como mais uma das áreas que compõem 'as artes' de um modo geral, sem maiores compromissos educacionais.

Tradicionalmente a educação musical faz (ou não) parte da disciplina curricular Artes, dividindo, 
compartilhando ou segregando algumas formas de manifestação artística em detrimento de outras. Em primeiro lugar é preciso entender que diferentes manifestações artísticas podem e devem ser tratadas por corpos teóricos distintos, e que cada uma destas manifestações conserva seu caráter individual e absolutamente particular. Por mais que se estabeleça uma aproximação em nível de discurso, tratando das artes no plural, é necessário que se respeite peculiaridades das manifestações artísticas, e que as estudemos com profundidade ${ }^{1}$. Sem a pretensão de se estabelecer qualquer hierarquia entre as artes, nem considerar qualquer uma delas como sendo mais arte do que a outra, é fundamental que se tenha clareza na definição, conceituação e aplicação de cada linguagem artística no contexto escolar.

Num passado bastante recente a tentativa da prática da polivalência da Educação Artística, confundiu vários aspectos das artes, em nome de uma simplificação quase absurda, onde se pretendia que um único indivíduo (professor polivalente) desse conta das várias linguagens artísticas na prática escolar. Este assunto parece que não precisa mais ser discutido pelos profissionais das artes na escola, mas a comunidade escolar, incluindo corpo administrativo, docente e discente, ainda sustenta uma visão de arte apoiada nos equívocos educacionais com relação às artes que foram implantados em diversos momentos da educação brasileira.

É facilmente compreensível que toda uma comunidade escolar ainda mantenha as mesmas idéias

\footnotetext{
1 Um exemplo comparativo pode ilustrar esta inter-relação entre as diversas áreas artísticas, de modo a preservar a identidade de cada uma delas. Quando se trata de língua estrangeira, entendese inglês, francês, espanhol e tantas outras, mas se compreende que cada uma delas exige tratamento particularizado. Há também relaçöes lingüísticas entre as várias línguas estrangeiras, mas somente estas relaçōes não dão conta da totalidade de cada língua em particular, e o professor de inglês năo é automaticamente o professor de francês.
} 
sobre ensino de artes já que há várias gerações não se realiza um trabalho sistemático e sério com relação a estas áreas do conhecimento. Mesmo quando em alguns momentos se tentou tratar arte como conhecimento, tal discurso se situava bastante restrito às Artes Plásticas (no movimento da Arte-Educação), o que entre outras questões, ocasionou uma predominância desta área artística nas escolas básicas brasileiras ${ }^{2}$.

\section{Um pouco da história da Educação Musical no Brasil}

Na história do Brasil temos exemplos de vários modelos trazidos da Europa e dos Estados Unidos para serem aplicados em nossa realidade. Excelentes modelos nem sempre demonstraram excelentes resultados em função da inadequação das propostas em situações diferentes das quais as mesmas foram concebidas e aplicadas com sucesso. Desde a vinda da família real para o Brasil, no início do século XIX, modelos musicais foram trazidos e aplicados, muitas vezes ignorando ou impedindo práticas musicais das culturas que aqui estavam ${ }^{3}$.

A tradição romântica européia foi instalada como sendo a referência para a sociedade brasileira não só no campo da música, evidentemente. Junto com a prática musical daquela época, foram trazidos também os conceitos musicais vigentes na Europa, como, por

\footnotetext{
${ }^{2}$ Evidentemente que năo se pretende aqui estabelecer um extenso discurso sobre a história da educação em artes, mas a predominância das Artes Plásticas no currículo significa, via de regra, pouca Educação Musical e Cênica, já que a grade horária para as artes é mínima, e não há profissionais de todas as linguagens artísticas disponiveis nas redes escolares, exceto a particular. Além disso, as escolas livres de música sāo muito mais atraentes que as escolas públicas em vários sentidos: os salários são melhores e o modelo pedagógico vigente é o conservatorial, que atende poucos alunos e raramente questiona a educação musical como um todo.

${ }^{3}$ Especialmente estamos nos referindo à música dos negros e índios brasileiros.
} 
exemplo, a ênfase na execução instrumental ou vocal, a questão do talento como requisito básico para se fazer música, a questão da virtuosidade, a questão do emocional versus o racional, a questão da música erudita como sendo a música séria, dentre outros. Tais aspectos que já se encontram tão distantes cronologicamente, ainda estão fortemente arraigados na cultura brasileira, oferecendo sérios entraves para o desenvolvimento de uma educação musical significativa e apropriada.

A concepção romântica de obra de arte propicia uma mistificação da atividade artística, localizando esta atividade como algo inexplicável, que por sua vez enfatiza a noção de gênio e genialidade enquanto dom natural, ou capacidade inata.

Nas palavras de Silva (1996):

"A obra de arte [no romantismo] era tida como resultado de uma força cósmica, orgânica, sem precedência, absolutamente desconhecida e imprevisível. Ser imaginativo representava transcender as peias da História e da Sociedade, cultivar uma essência que estava acima dos homens e de sua vida diária. Assim, a concepção romântica termina apartando a arte do convívio dos homens, porque se transformara numa entidade totalmente misteriosa, regida por leis fantásticas." (p. 110)

Nos dias de hoje a visão romântica parece ser mais conveniente para justificar inclusive a ausência de clareza pedagógica em artes. É como se não fosse possível atingir tal clareza pedagógica, confirmando que arte é para uns poucos privilegiados. A visão romântica também "mascara e legitima as condições socialmente diferenciadas de acesso à arte." (Penna, 1998, p. 50)

Na primeira metade do século XX, em diferentes partes do mundo surgiram propostas educacionais em 
música que em linhas gerais pretendiam questionar a abordagem que se praticava até aquele momento. No Brasil os ecos destas propostas se fizeram ouvir através do Canto Orfeônico, movimento proposto por VillaLobos, que pretendia atingir todas as escolas brasileiras com a prática do canto em grupo. Os professores que trabalharam com Villa-Lobos eram oriundos dos conservatórios de música, que de um modo geral preservavam toda a tradição européia no que diz respeito aos conceitos sobre música e educação musical. O Canto Orfeônico seguia

"um modelo tradicional, baseado em processos imitativos, direcionados aos objetivos e metas do programa determinado, e que explorava o aspecto funcional da música em direção ao sistema governamental vigente" (Oliveira e Hentshke, 2000, pág. 47 e 48).

Na prática a proposta de Villa-Lobos teve uma alcance limitado aos centros de maior desenvolvimento do país e se sustentou durante a época da ditadura Vargas, desaparecendo com o advento do Estado Novo.

Na década de 1970, a Lei 5692/71 instituiu a Educação Artística no Ensino Fundamental em seu caráter polivalente, incentivando a formação de profissionais para atuarem nesta área de ensino. A experiência da polivalência trouxe resultados insatisfatórios e não contribuiu para o estabelecimento de uma proposta consistente para as artes na educação em geral. Neste contexto as Artes Plásticas se estabeleceram como área hegemônica nos sistemas educacionais e música é considerada sempre como a 'mais difícil' das artes e aquela que solicita 'muito talento'.

Nos dias de hoje, apesar de tanta discussão acumulada e produção de inúmeros debates em torno dos problemas da Educação Artística, estão presentes vários equívocos sobre arte e seu ensino, e muitos deles ainda relacionados à visão romântica de arte. Neste 
contexto, a educação musical ainda é privilégio de poucos e é muito comum que música seja oferecida como atividade extracurricular, não pertencendo ao corpo de conhecimento considerado imprescindível para a formação dos indivíduos.

\title{
As Novas Legislações
}

\section{Lei de Diretrizes e Bases}

\begin{abstract}
A Nova Lei de Diretrizes e Bases da Educação Nacional (LDB, Lei 9394 de 1996) apresenta proposições para o ensino das artes nas escolas.

"O ensino de arte constituirá componente curricular obrigatório, nos diversos níveis da educação básica, de forma a promover o desenvolvimento cultural dos alunos" (LDB, 1996, artigo 26).
\end{abstract}

No entanto tal obrigatoriedade é livre para entendimentos diversos. Como componente curricular pode-se entender que conteúdos artísticos farão parte das atividades escolares, e não se garante a presença de disciplinas para o desenvolvimento das artes. Por exemplo, cantar uma música folclórica numa atividade de Estudos Sociais poderia caracterizar a presença da música como componente curricular. Ou ainda, cantar para lavar as mãos ou para escovar os dentes também poderia ser entendido como componente musical na atividade escolar. Pode-se concluir que tal texto da lei não garante a presença das artes nos currículos escolares de maneira significativa. Até hoje as experiências de ensino de artes nas escolas brasileiras não deram conta de estabelecer uma consciência da importância ou da necessidade das artes no desenvolvimento dos indivíduos que freqüentam as escolas, e não se pode ingenuamente acreditar que por causa de um parágrafo da LDB as mudanças de concepção serão imediatamente elaboradas, implementadas e aceitas por uma comunidade desabituada de tal situação. 


\section{Documentos Curriculares Referenciais}

Os Parâmetros Curriculares Nacionais (PCNs), o Referencial Curricular para a Educação Infantil e também o documento referencial para o Ensino Médio derivam das reformas propostas pela Nova LDB. Dirigidos para os diversos segmentos da Educação Básica, os documentos mencionados apresentam proposições para o ensino das artes. Não se adota mais o termo Educação Artística, talvez na tentativa de solicitar mudanças conceituais, mas não se apresenta qualquer proposta de aplicação para as quatro áreas artísticas indicadas em tais documentos (Música, Artes Plásticas, Teatro e Dança). A ausência de proposta única sobre a aplicação das artes é um indicador da complexidade desta situação que está sendo devolvida para a comunidade escolar com o respaldo da LDB quando apresenta:

"Os estabelecimentos de ensino, respeitadas as normas comuns e as dos seus sistemas de ensino, terão a incumbência de elaborar e executar sua proposta pedagógica." (LDB, 1996, artigo 12).

Pode ser uma tarefa estimulante estabelecer de que forma se dará a presença do ensino das artes nas escolas, mas ao mesmo tempo isto pode significar a autorização para se fazer pouco ou quase nada diante desta situação. As escolas em geral não estão equipadas para atender de forma satisfatória as atividades artísticas: música faz barulho, artes plásticas faz sujeira, e assim por diante, e tais formas de pensar podem significar a manutenção da ausência das diversas linguagens artísticas na escola. Não há profissionais das várias linguagens nas escolas, e as mesmas podem decidir pela permanência desta situação já que a lei autoriza tal procedimento. Na grade curricular não estão previstas aulas para todas as linguagens, e na melhor das hipóteses, nas escolas onde há professores de diferentes linguagens artísticas, poderá ser proposto um rodízio de professores em cada ano escolar, promovendo vivências variadas, porém, descontínuas. 
Além destas questões que dependem de administração e políticas educacionais sérias, é importante ressaltar que os textos de vários destes documentos apresentam problemas de fundamentação e concepção de arte. Reflexões extremamente importantes sobre as concepções de arte nos PCNs estão apresentadas pelo Grupo de Estudos do Departamento de Artes da UFPB (Penna, 1998), compondo literatura imprescindivel para subsidiar discussões nesta área.

A transformação desejada por alguns profissionais do ensino das artes parece estar muito distante da realidade apresentada, pois depende de várias ações que derivam de reflexões e concepções de arte que ainda não fazem parte dos sistemas de ensino de um modo geral.

\section{Especialistas versus generalistas}

Os professores especialistas de cada área artística na escola aboliram a prática da polivalência há muito tempo. Ao mesmo tempo que se compreendeu a impossibilidade de um único profissional desenvolver diversas linguagens artísticas a partir de uma formação inadequada para tal fim, estabeleceu-se também uma prática individualizada, favorecendo a fragmentação de conteúdos pertencentes ao universo escolar. Hoje em dia quando se fala em integração em artes imediatamente se pensa em polivalência, provocando distanciamentos cada vez maiores das artes em relação a elas mesmas e à educação como um todo.

Em educação musical parece que não se pode pensar em música além de ensinar um instrumento musical, e quem não conhece grafia musical convencional é considerado leigo ${ }^{4}$. É muito comum

\footnotetext{
${ }^{4}$ Nāo se pretende aqui desvalorizar a importância da notaçāo musical tradicional, mas é preciso ampliar esta discussāo para outros tipos de notação musical também existentes como formas de registros sonoros vários.
} 
ouvirmos pessoas dizendo 'eu não entendo nada de música' quando estão se referindo apenas a alguns aspectos da música, como por exemplo signos da notação musical tradicional ou a execução instrumental. Concordando com Hodges (1996) tal indivíduo leigo, ou não músico, não existe porque todos os indivíduos respondem de alguma forma aos estímulos da música de sua cultura.

Considerar-se não músico em termos educacionais tem impedido que a música pertença ao universo escolar de maneira objetiva. Este sentimento de incapacidade musical está muito presente entre os professores generalistas, aqueles que trabalham todas as áreas do conhecimento escolar com uma turma, e os mesmos raramente incluem música em suas atividades de forma consciente e crítica. O resultado deste estranhamento que se estabelece em relação à música na educação é um dos fatores que contribuem para o distanciamento cada vez maior das questões musicais no contexto escolar. É preciso romper com este círculo vicioso e redimensionar o papel da música na escola para que as futuras gerações estejam alfabetizadas musicalmente. A publicação "Ler e escrever: compromisso de todas as áreas" (Neves, org.,1999) organizada por profissionais de diversas áreas do ensino, inclui a música de maneira muito precisa e pode contribuir para a compreensão de que ensinar a ler e a escrever é tarefa de todas as áreas.

É preciso que se organize um espaço de discussão para a música na escola e tal espaço não depende exclusivamente do especialista em música. Os professores generalistas que atuam desde a Educação Infantil, podem contribuir para o desenvolvimento musical. Mills (1991) reforça a idéia de que "é perfeitamente possível engajar crianças com a música sem ser pianista." (pág. 2). Trabalhar integradamente não significa invadir territórios alheios 
desde que se trate desta questão com profissionalismo e objetividade. Os professores especialistas e generalistas podem trabalhar juntos para construir um espaço educacional que incorpore e legitime a educação musical como área de conhecimento.

\section{O que podemos fazer?}

Um passo fundamental para que se mude o quadro existente, refere-se sem dúvida à reflexão e ação dos profissionais da educação. Quais säo os elementos constitutivos de uma prática docente efetiva? O que cada educador pode fazer em suas atividades para contribuir para o estabelecimento de uma educação melhor? Neste sentido pode ser útil resgatar parte do conteúdo de um informe da UNESCO de 1966:

“... se considera que a função docente é uma profissāo com caráter de serviço público que exige como requisitos:

- uma forma concreta de vocação pedagógica;

- o convencimento de que esta carreira nunca está terminada e, por conseguinte, deve-se ter uma atitude favorável à formação permanente;

- consciência de que esta profissão está exposta a opiniōes sociais muito diversas." (apud Fuentes e Cervera, 1989, pág. 126)

Cada educador deve se conscientizar de seu papel num contexto educacional que é muito maior do que sua disciplina na grade curricular, estabelecendo relações constantes entre diferentes aspectos do conhecimento escolar.

Também é preciso se livrar do pessimismo com relação à escola em geral, fator que tem prejudicado a motivação dos profissionais da educação no sentido de acreditar sempre na possibilidade de uma educação melhor. Expressões do tipo: a educação brasileira está muito ruim e não vai mudar, ou não tem jeito de melhorar a educação porque não somos fortes contra o sistema estabelecido, ou ainda eu já tentei, 
mas agora desisti de fazer alguma coisa para melhorar a educação, devem ser evitadas e principalmente combatidas nos diferentes segmentos educacionais.

Se a educação brasileira está ruim cabe aos educadores uma parcela de responsabilidade com relação às mudanças desejadas; cada um deveria assumir a sua parte nesta tarefa, mas é sempre mais cômodo considerar que a culpa é dos outros.

Se não somos fortes sozinhos para enfrentarmos o sistema estabelecido, precisamos nos unir para encontrarmos saídas que transformem efetivamente a realidade educacional. Há muitas experiências positivas espalhadas pelas escolas brasileiras; há muita pesquisa em educação musical e em artes que poderiam contribuir para o estabelecimento de argumentos mais sólidos com relação à necessidade da formação em arte nos sistemas educacionais.

E quem está cansado porque já tentou muita coisa sem muito sucesso deveria reavaliar sua permanência no sistema educacional lembrando sempre que atuar em educação 'dá trabalho'. Tal situação está pontualmente discutida pela pesquisadora em educação musical Regina Santos (1995), que sintetiza: "ou se permanece em educação por falta de opções, ou se permanece por convicção." (pág. 29).

A presença da educação musical e das artes nas escolas depende de uma ação coletiva da comunidade educacional. Os professores de artes são poucos no sistema educacional exatamente pela pequena quantidade de carga horária destinada a estas disciplinas. Um primeiro passo está relacionado ao que se pretende fazer com música na escola, com arte na escola, e que espaço curricular está destinado para isso. Um exemplo de que transformações desta natureza podem ocorrer está localizado na rede pública 
municipal de Florianópolis. Após alguns anos de parceria entre o Centro de Artes da UDESC e a Secretaria Municipal de Educação, hoje a realidade que se apresenta é, no mínimo, promissora.

- a administração escolar compreendeu a individualidade das artes e tem se esforçado para oferecer diferentes linguagens artísticas na rede escolar;

- os concursos para contratação de professores das diversas linguagens têm sido dirigidos para cada habilitação, eliminando definitivamente o ranço da polivalência em artes na escola; o que se espera é oferecer para as escolas gradativamente pelo menos três linguagens artísticas: Música, Teatro e Artes Plásticas; em algumas unidades escolares estão presentes duas linguagens atualmente;

- a grade horária apresenta duas ou três aulas semanais para Artes, dependendo da série, diminuindo significativamente o desequilíbrio entre as áreas do currículo;

- um projeto de capacitação continuada para professores da rede municipal tem ocorrido, contribuindo para o estabelecimento de uma prática de ensino das artes mais consistente;

- os resultados desta ação se fazem presentes nas avaliações gerais e várias escolas têm solicitado a presença de mais profissionais das artes na rede escolar.

Este é um exemplo, e seguramente existem outros que podem servir como apoio para outros segmentos educacionais. Portanto, depende de uma ação coletiva a inserção das artes na proposta pedagógica da escola. É necessário que os profissionais das artes ocupem espaços e apresentem argumentos para a implantação 
e permanência de projetos pedagógicos nas escolas e em outros espaços educacionais. A participação da comunidade escolar e da comunidade em geral é imprescindível para que se re-estabeleça o papel das artes na educação, incluindo nesta participação a universidade e os centros de ensino formadores dos profissionais das artes.

Ainda nesta linha de pensamento sobre a ação coletiva para a educação, a publicação "Projetos para Escola", organizada por J. Souza (2000), traz a síntese de um projeto de capacitação continuada no estado do Rio Grande do Sul, cujos resultados destacam a importância de vários aspectos educacionais, além das disciplinas do currículo.

Ao se incluir a comunidade escolar e a comunidade em geral, o que se pretende é o resgate cultural através de diálogos e ações conjuntas que contribuam para a ampliação do universo artístico de todos os indivíduos. É um processo de re-significação do papel das artes na formação dos indivíduos. Tal ação é importante e indispensável, já que vivemos em uma sociedade que vem sendo privada do acesso a muitos bens artísticos da humanidade. Para que esta sociedade reveja conceitos e pontos de vista acerca das artes é fundamental que a experiência artística na escola irradie e atinja outros segmentos sociais. Z. Kodály, eminente educador musical húngaro responsável por um método conhecido mundialmente, considerava que se a experiência musical com as crianças na escola fosse significativa, elas levariam para suas casas tal significação, envolvendo os pais, amigos e vizinhos de tal forma que haveria uma real disseminação da cultura musical entre as pessoas (Szony, 1990).

\section{Considerações finais}

O panorama que foi apresentado neste texto chama a atenção para muitos problemas da educação 
musical, mas aponta caminhos encontrados para a administração da música em escolas. O que se torna bastante claro ao longo da história é que os modelos educacionais têm sido adotados muitas vezes sem o conhecimento suficiente para que se fundamente uma prática educacional relevante. Temos nos contentado com alguns aspectos de cada modelo educacional e chamamos a isso de ecletismo. Usa-se o instrumental Orff, o repertório Kodály, a prática instrumental Suzuki e talvez a inventividade proposta por Schafer, mas se conhece muito pouco dos fundamentos epistemológicos de cada método em educação musical. Desta forma temos situações conflitantes do ponto de vista educacional tratadas sem qualquer cuidado. Uma escola que se diz construtivista pode adotar o modelo Suzukiano da aprendizagem por imitação? Numa perspectiva sócio-interacionista as crianças devem ter como meta a execução instrumental de um repertório convencional fixo que considera a aprendizagem de um instrumento independente do indivíduo que aprende?

O que se apresenta com freqüência é ainda uma compreensão musical limitada tanto do ponto de vista do contexto educacional que reforça questões do senso comum sobre música e seu ensino, quanto por parte dos educadores musicais que perpetuam práticas tradicionais. O problema central parece estar relacionado aos modelos paradigmáticos vigentes. Por exemplo, para se estudar música numa concepção tradicional é preciso ter talento em primeiro lugar, dedicação e muita disciplina para tocar um instrumento virtuosisticamente, e se trabalha muito na busca da imitação de interpretações consideradas referências para os músicos. Desta forma se passa grande parte da vida de estudante de música tentando 'tocar que nem fulano' que é autoridade nesta área. Professor de música é aquele que toca bem, desconsiderando qualquer perspectiva pedagógica para se ensinar música. Pouco se estuda sobre música num sentido 
mais amplo, além daqueles aspectos relacionados à teoria básica (notas musicais, grafia musical, e outros) ou informações enciclopédicas sobre datas, nomes e números de obras. Também se trabalha pouco a questão da criação musical, que retro-alimenta a composição como resultado da genialidade e dos mistérios da arte. O professor de música deveria ousar diante destas questões tão aceitas tacitamente no sentido de acreditar na existência de outros caminhos possíveis, além de "abrir-se às múltiplas possibilidades desses caminhos." (Santos, 1995, pág. 30)

Que educação musical queremos? Se os modelos adotados parecem não suprir as necessidades deste momento histórico, em pleno século XXI, devemos buscar outros modelos, ou quem sabe devemos abolir modelos.

\section{Referências Bibliográficas}

BRASIL. Referencial curricular nacional para a educação infantil. Secretaria de Educação Fundamental. Brasília: MEC/SEF, 1998.

BRASIL. Parâmetros curriculares nacionais - $1^{a} a 4^{a}$ série. Secretaria de Educação Fundamental. Brasília: MEC/ SEF, 1998.

BRASIL. Parâmetros curriculares nacionais: Arte - $5^{a}$ a $8^{a}$ série. Secretaria de Educação Fundamental. Brasília: MEC/SEF, 1998.

FIGUEIREDO, S. L. F. Proposta curricular de música para o município de Florianópolis. Anais do III Encontro Regional Sul da ABEM e /l Seminário de Educação Musical da UDESC. Florianópolis: UDESC, 2000. (On Line: http://www.udesc.br/centros/ ceart/arteonline) FUENTES, P. \& CERVERA, J. Pedagogia y didática para músicos. Valencia: Piles, 1989.

HENTSCHKE, L. \& OLIVEIRA, A. A educação musical no Brasil. In L. Hentschke (org.), Educação musical em países de línguas neolatinas (pp. 47 a 64). Porto Alegre: UFRGS, 2000. 
HODGES, D. A. (Ed.) Handbook of music psychology $\left(2^{\text {nd }}\right.$ ed.). San Antonio: Institute for Music Research (IMR), 1996.

MILLS, J. Music in the primary school. Cambridge: Cambridge University Press, 1991.

NEVES, C. B. et al (org.) (1999). Ler e escrever: Compromisso de todas as áreas. Porto Alegre: UFRGS, 1999.

PENNA, M. (org.). Os parâmetros curriculares nacionais e as concepçōes de arte. Caderno de Estudos n. 15. Paraíba: UFPB, 1998. (Grupo de Estudos do Departamento de Artes do Centro de Ciências Humanas, Letras e Artes da UFPB)

SANTOS, R. M. S. Crítica, prazer e criação musical no ensino-aprendizagem musical. Anais do $4^{\circ}$ Simpósio Paranaense de Educação Musical. Londrina: UEL, 1995. SAVIANI, D. A nova lei da educação: Trajetória, limites e perspectivas (3. ed.). São Paulo: Autores Associados, 1997.

SOUZA, J. (org.) Projetos na escola: Registro de uma experiência em formação continuada. Porto Alegre: UFRGS, 1999.

SZÖNYI, E. Kodály's principles in practice: An approach to music education through the Kodály Method. Budapest: Corvina, 1990. 